\title{
Discussion and Analysis on Measurement Methods for Mould Friction during High Efficiency Continuous Casting
}

\author{
Yong Ma ${ }^{1, \text { a }}$, Fangyin Wang ${ }^{1}$, Bohan Fang ${ }^{1}$ and Wei Gui ${ }^{1}$ \\ ${ }^{1}$ School of Materials Science and Engineering, Hefei University of Technology, Hefei 230009, China \\ ${ }^{\text {a }}$ Corresponding author
}

\begin{abstract}
The friction between the mould and slab has important influences on the process of continuous casting and the slab quality. In this paper, based on the continuous slab caster under hydraulic oscillation, the measurement methods of mould friction are studied. The extraction and realization of friction work method and pressure method are discussed, and the relationship of measured parameters of two methods is deduced in theory. On the basis of the measured data in continuous slab casting, the friction measured parameters are calculated by the two measurement methods in different conditions, and the comparative analyses on the advantages and applicability of the two measuring methods are performed. The research provides theoretical and experimental bases for the reasonable selection and application of friction measurement method.
\end{abstract}

\section{Introduction}

With the development of high efficiency continuous casting technology, high casting speed results in a lower rate of powder consumption and the severe quality of slab surface. It promotes researchers to pay more attention to studying the behavior of lubrication and the friction between the mould and the initial solidified strand shell. The mould friction as an important factor to reflect the lubrication condition between the mould and strand not only has influence on the surface quality of slab and the stable production but also has the great application potential on estimating the lubrication effect of powders, predicting the breakout and improving the slab quality. [1].

Based on the traditional mechanical oscillator, several measurements and analysis methods have been applied or proposed to quantify mould friction and many achievements have been obtained [1-2], such as power method, force sensor method, acceleration measurement, etc. [3]. In recent years, the hydraulic oscillator is developed and meets the requirements to the control of mould oscillation for high efficiency continuous casting technology [4]. At present, the on-line detection of friction is realized with the hydraulic oscillation, and the typical methods are listed as shown in Ref.5-6. However, only a few papers are devoted to a further step for the study of the difference and relationship between these measuring methods. Papers dealing with measurements of mould friction are mainly for the prevention of breakouts in the continuous casting of slabs, these methods seem not to be applicable in some case of continuous casting such as the higher casting speed working conditions.

According to the differences of the measurement principle and the detection parameters, the method developed by VAI is named friction work method. And the other method is called pressure meth ${ }^{i}$ od. In the present work, the analysis and discussion are carried out from the measurement principles and features based on the two measurement methods above mentioned. Meanwhile, based on the measured data come from a slab caster with a hydraulic oscillation system, the results of friction are compared and analyzed by the two methods in different conditions. The variations and characteristics of mould friction are researched. Details of this study are described in this paper.

\section{Experimental conditions}

The research has been carried out on the slab continuous casting machine driven by the hydraulic oscillator. The main characteristics of the machine are given in Table 1. In this work, a large amount of data are detected at the same oscillation parameters, including driving force, displacement, casting speed and so on, which are necessary for mould friction measuring. In this paper, the sampling rate is between 500 and $1250 \mathrm{~Hz}$, which is high enough to prove the reliability of the measurement of friction values for each oscillation period, and which provides sufficient data guaranteed for friction measurement and calculation.

Table 1. Main characteristics of the slab continuous casting machine

\begin{tabular}{|c|c|}
\hline Machine type & Vertical bending \\
\hline Mould length, mm & 1000 \\
\hline Machine radius, $\mathrm{m}$ & 5 \\
\hline Number of strands & 1 \\
\hline Metallurgy length, $\mathrm{m}$ & 14.74 \\
\hline Mould length, mm & Powder \\
\hline Lubrication & $\begin{array}{c}\text { Sinusoidal, } \\
\text { non-sinusoidal }\end{array}$ \\
\hline Oscillation type & Electro-hydraulic servo \\
\hline Oscillator type & 2 \\
\hline Cylinders & \pm 5 \\
\hline $\begin{array}{c}\text { Maximal oscillation } \\
\text { stroke, mm }\end{array}$ & 400 \\
\hline $\begin{array}{c}\text { Maximal oscillation } \\
\text { frequency, cycles per } \\
\text { min-1 }\end{array}$ & \\
\hline
\end{tabular}

\section{Method of friction extraction}

Mould friction is generated in both with casting conditions and without casting conditions. When the mould oscillated in the empty state (no casting), the load is composed of 
oscillator mass and the loss of transmission system. While for the casting state, the load also includes the interaction of the mould and strand. The friction is zero during no casting, so the difference of driving forces between casting (HOT) and no casting (COLD) at the same oscillation parameters represents the mould friction. And both pressure method and friction work method follow this friction measuring thought.

With pressure method, MDF can be obtained by difference of the driving force of mould between casting and no casting state in the same oscillation condition. The calculating method is like equation(1)[5]. $F t_{H o t}$ can be continuously measured by the pressure transducers on-line during casting. $F t_{\text {Cold }}$ which describes the necessary force to move the idle mould under equal oscillation condition during no casting also can be obtained by the pressure transducers on-line during no casting.

From the viewpoint of energy, friction work method measures the average friction in an oscillation cycle by calculating the work of cylinders driving force in an oscillation cycle of both casting and no casting state in the same condition, as equation(2)[5]. And $W_{\text {Hot }}$ and $W_{\text {Cold }}$ can be directly obtained by equation(3) and (4), separately.

$$
\begin{gathered}
M D F=F t_{\text {Hot }}-F t_{\text {Cold }} \\
M D F_{\text {(work) }}=\frac{W_{\text {Hot }}-W_{\text {Cold }}}{4 s} \\
W_{\text {Hot }}=\oint_{\text {Cycle }} F t_{\text {Hot }} d y \\
W_{\text {Cold }}=\oint_{\text {Cycle }} F t_{\text {Cold }} d y
\end{gathered}
$$

Where, $M D F$ means mould friction $(\mathrm{kN}), F t_{H o t}$ means driving force during casting $(\mathrm{kN}), F t_{\text {Cold }}$ means driving force during not casting $(\mathrm{kN}), M D F_{(\text {work })}$ means average mould friction $(\mathrm{kN}), W_{\text {Hot }}$ means physical work by $F t_{H o t}\left(\mathrm{kN}^{*} \mathrm{~mm}\right), W_{\text {Cold }}$ means physical work by $F t_{\text {Cold }}\left(\mathrm{kN}^{*} \mathrm{~mm}\right), s$ means oscillation amplitude $(\mathrm{mm})$, y means displacement ( $\mathrm{mm})$.

\section{Results and Discussions}

\subsection{Variations of mould friction}

Figure.1 (b) shows the transient friction, which is obtained by pressure method at normal production, as well as $F t_{\text {Hot }}$ and $F t_{\text {Cold }}$. Mould friction varies regularly with the oscillation velocity as shown in figure.1 (a). The sign of friction is either negative or positive following the velocity direction. During the positive strip time, the mould moves upward towards casting slab and results in positive friction, which is interpreted as a force leading to tensions on the surface of the strand shell and is able to lead to surface defects. On the other hand, during the negative strip time (tn), the casting mould moves downwards casting slab and results in negative friction, which exerts compressive force on the strand surface and is necessary for the healing of surface defects. The studies we have performed showed that friction calculated by pressure method can describe the transient lubrication condition of the mould power in detail.

The enclosed area in the force versus displacement plot is called the indicator diagram as shown in figure.1(c), the physical work by $F t_{\text {Hot }}$ or $F t_{\text {Cold }}$ per oscillation cycle, e.g. the casting and no casting. Work done by friction can be obtained by the difference of physical work of driving force between casting and no casting at the same oscillation condition, which is named the friction work $\left(W_{M D F}\right)$. And according to the equation(2), the average mould friction can obtained as shown in figure.1(d).
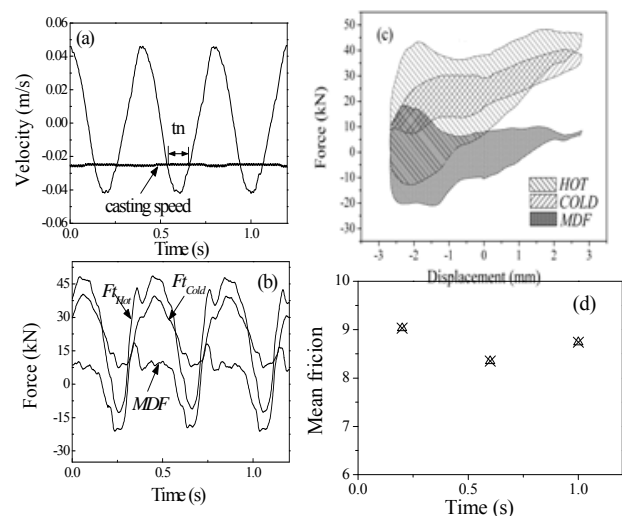

Figure.1 (a) Casting speed and velocity of the mould, (b) Friction extraction, (c) Force versus displacement and (d) Average friction (frequency $150 \mathrm{cpm}$, stroke $3 \mathrm{~mm}$, casting speed $=1.5 \mathrm{~m} / \mathrm{min}$, sinusoidal mode)

\subsection{Relation between detection results}

In equation(2), the result of $\left(W_{H o t}-W_{\text {Cold }}\right)$ can be called the physical work of mould friction $\left(W_{M D F}\right)$ as shown in equation(5). So equation(2) can be written as equation(6). Similar to calculation method of $W_{H o t}$ or $W_{\text {Cold }}, W_{M D F}$ could also be obtained according to equation(7) with the data of transient mould friction (MDF). So the average friction can also be calculated by equation( 8$)$. In this paper, $M D F_{(\text {friction })}$ is used to indicate the average friction calculated by the transient friction with equation(7) and equation(8). In theory, $M D F_{\text {(friction) }}$ and $M D F_{\text {(work) }}$ should be equal as shown in equation(9). That is, the average friction obtained by friction work method should be equal with the average friction which is calculated by pressure method. $W_{M D F}$ establishes the relationship between pressure method and friction work method theoretically.

$$
\begin{gathered}
W_{M D F}=W_{\text {Hot }}-W_{\text {Cold }} \\
M D F_{(\text {work })}=\frac{W_{\text {Hot }}-W_{\text {Cold }}}{4 s}=\frac{W_{M D F}}{4 s} \\
W_{M D F}=\oint_{\text {Cycle }} M D F d y
\end{gathered}
$$




$$
\begin{gathered}
M D F_{(\text {friction })}=\frac{W_{M D F}}{4 s} \\
M D F_{(\text {work })}=M D F_{(\text {friction })}
\end{gathered}
$$

Where, $W_{M D F}$ means physical work of mould friction $\left(\mathrm{kN}^{*} \mathrm{~mm}\right), \quad M D F_{(\text {friction })}$ means the average friction calculated by the transient friction $(\mathrm{kN})$.

In order to prove the correctness of equation(9), based on the actual measurement data, transient friction(MDF), $M D F_{(\text {work })}$ and $M D F_{\text {(friction) }}$ are calculated during the stable continuous casting period as shown in figure.2. According to equation(7) and equation(8), $M D F_{(\text {friction })}$ is calculated by transient frictionas shown in figure.2(a). As seen from figure.2(b), the trend of $M D F_{(\text {work })}$ is the same as Work $_{(H o t)}$. Specially not only the variation tendency of $M D F_{\text {(friction) }}$ but also the value is consistent with that of $M D F_{(\text {work) }}$. The calculated result by detected data corroborated the theoretical conclusion, which confirms that equation(9) is correct. A meaning result that to some extent, the test results of friction by the two measuring methods can be interchangeable according to the necessaries of testing or research, can be obtained.
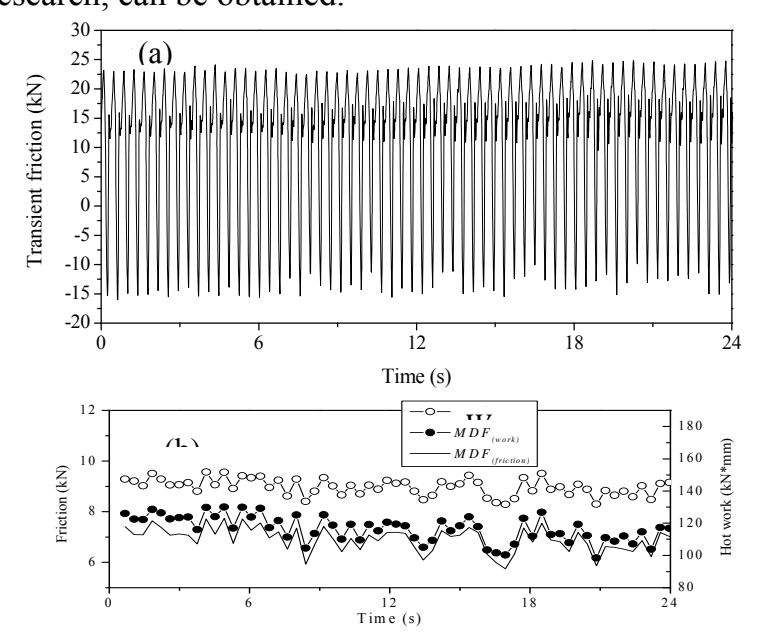

Figure.2 Distributions of (a) transient friction and (b) Work (Hot) $_{\text {, }}$, $M D F_{(\text {work }}$ and $M D F_{\text {(friction) }}$ during the stable continuous casting period (non-sinusoidal mode, frequency $154 \mathrm{cpm}$, amplitude $2.8 \mathrm{~mm}$, casting speed $2.1 \mathrm{~m} / \mathrm{min}$, deviation angle $10^{\circ}$ )

\subsection{Effect of casting speed on mould friction}

On the basis of researches produced, the casting speed has a great effect on the lubrication behavior. In this paper, the effect of abrupt change in casting speed on lubrication behavior is analyzed, as shown in figure.3. In figure.3(a), the transient friction variation with time can also be seen clearly. But in $6 \sim 12 \mathrm{~s}$, the change of casting speed do not make significant changes either on periodical character or friction value.

In contrast, the average friction measured by friction work method shows the obvious fluctuation as shown in figure.3(b). There is a short strong friction peak during the abrupt change period of casing speed. According to the field operation records, there are no special operations during this period. One possible explanation may be the influence of the abrupt change of casting speed. The serious and transient variation of casting speed will lead to strong fluctuation of meniscus, meanwhile, the heat transfer and lubrication of different parts of mould will be influenced by the abrupt change of casting speed, which may promote a non-uniform heat transfer and lubrication. Therefore a sharp increment of the friction level maybe occurs because of the abrupt varying of casting speed and the fluctuation of mould level.

Considering the effect of friction on slab, in one oscillation cycle, according to the transient friction data, the average positive friction can be calculated in equation(10) and the average negative friction can be similarly calculated in equation(11). In figure.3(b), $M D F_{(+)}$ presents the similar trend with average friction as well as $M D F_{(-)}$fluctuates obviously with the casting speed. In summing up it may be stated that the average friction has relative higher sensitivity than that of pressure method in the aspect of reflecting the lubrication between the mould and strand when casting speed is changed. The transient friction measured by pressure method does not make clear reflection when casting speed changes suddenly. However, the $M D F_{(+)}$and $M D F_{(-)}$, which obtained from the transient friction have made the significant reflection, which shows the higher sensitivity similar to the average friction .

$$
\begin{aligned}
& M D F_{(+)}=\frac{\sum_{i=1}^{n 1}\left(M D F_{(\geq 0)}\right)_{i}}{n 1} \\
& M D F_{(-)}=\frac{\sum_{i=1}^{n 2}\left(M D F_{(\leq 0)}\right)_{i}}{n 2}
\end{aligned}
$$

Where, $M D F_{(+)}$is average positive friction in one cycle $(\mathrm{kN})$, which is interpreted as the average force leading to tensions on the strand. $M D F_{(\geq 0)}$ is every positive friction and $n 1$ is the sampling point of positive friction in one cycle. $M D F_{(-)}$is average negative friction in one cycle $(\mathrm{kN})$, which exerts average compressive force on the strand surface. $M D F_{(\leq 0)}$ is every negative friction and $n 2$ is the sampling point of negative friction in one cycle. And according to the two friction measurement methods, the relations of the detection parameters are shown in figure.4. 

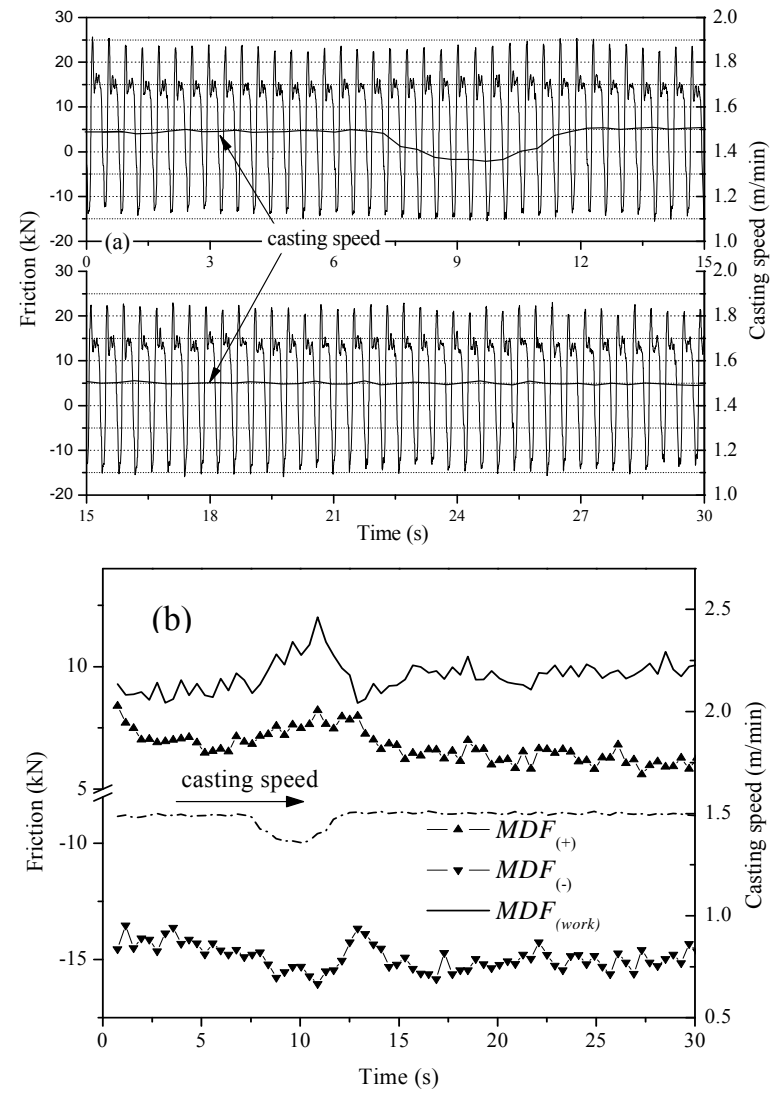

Figure.3 Variations of (a) transient friction (b) average friction, tensile friction and pressure friction during the casting speed change period

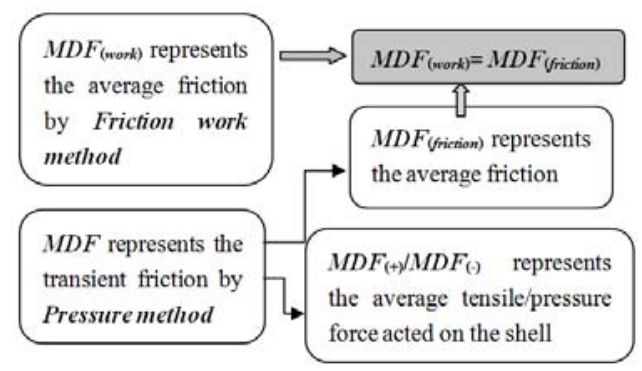

Figure.4 Relation of the calculated parameters according to the two methods

\section{Conclusion}

(1) The variation of transient friction calculated by pressure method is nearly similar to the variation of oscillation velocity with time. And the tensile force acted on the surface of strand can make a most telling exposure as well as the pressure force. In summary it may be stated that the transient lubrication between the mould and strand can be performed and researched carefully by the result of pressure method.

(2) The friction obtained by friction work method, reflects the combined effects on slab surface from the perspective of energy. The friction characteristics for long time trend are obvious and captured easily online with the changing of casting speed and other parameters. It can be confirmed that the $M D F_{\text {(work) }}$ and $M D F_{\text {(friction) }}$ are closed and the detection parameters not only theoretically but also experimentally, can be transformed into each other under the certain conditions.

\section{References}

[1]Y. Man, D.C.Fang, IRONMAK STEELMAK, On Line Measuring Method for Mould Friction in Continuous Casting, 23, 19-23(1996)

[2] J. Watzinger, A. Pesek, N.Huebner, M.Pillwax and O.Lang, IRONMAK STEELMAK, MoldExpert operational experience and future development, 32, 208 (2005)

[3] K.E.Blazek, I.G.Saucedo, ISIJ International, Characterization of the formation, propagation, and recovery of sticker/hanger type breakout, 30, 435-443 (1990)

[4] M. Yong, W. Xudong, Zang et al, IRONMAK STEELMAK, Mould lubrication and friction behaviour with hydraulic oscillators in slab continuous casting, 37, 112-118(2010)

[5] Watzinger J, Flick A, Slab Casting Session, VAI's online mold friction monitoring system in continuous casting, 6, 17-23(2000)

[6] Carlos C, Constanino C, Angel C, Mauel B, Luis F, Iron and Steel Technology, Analysis of mold friction in a continuous casting machine of round bars, 7 , 45-51 (2006) 